\title{
Rheological Behavior of Sumac (Rhus coriaria L.) Extract as Affected by Temperature and Concentration and Investigation of Flow Behavior with CFD
}

\author{
Adnan Bozdogan ${ }^{1 *}$ (D), Kurban Yasar ${ }^{1}$ (D), Mustafa Soyler ${ }^{2}$ (D) Coskun Ozalp $^{2}$ (D) \\ 1 Osmaniye Korkut Ata University, Department of Food Engineering, Osmaniye, Turkey ${ }^{2}$ bozdogan@osmaniye.edu.tr, \\ kurbanyasar@osmaniye.edu.tr; \\ 2 Osmaniye Korkut Ata University, Department of Energy Systems Engineering, Osmaniye, Turkey, \\ mustafasoyler@osmaniye.edu.tr; coskunozalp@osmaniye.edu.tr; \\ * Correspondence: bozdogan@osmaniye.edu.tr;
}

Received: 10.05.2020; Revised: 2.06.2020; Accepted: 3.06.2020; Published: 7.06.2020

\begin{abstract}
The purpose of this study is to investigate the rheological properties of sumac extract in different concentrations at different temperatures as well as its flow behavior in sudden expansioncontraction and at $90^{\circ}$ elbow with CFD. The rheological behaviour of sumac extract in different concentrations $(45.65 \%, 50.44 \%, 55.53 \%, 60.32 \%$, and $65.13 \%$ total solids) were evaluated using a rotational viscometer at different temperatures $\left(10,20,30,40\right.$ and $\left.50{ }^{\circ} \mathrm{C}\right)$. Sumac extract samples showed Newtonian flow properties in these temperature ranges. Arrhenius equation was used to determine the effect of temperature. Ea value varied in the range of 11.16-34.35 kJ/mol, which diminished with a decrease in concentration. Power and Exponential models were used to characterize the effect of concentration on flow behavior. Time average velocity vector and contours, vorticity contours, kinetic energy contours, and pressure contours are given to show the flow behavior of sumac extract.
\end{abstract}

Keywords: Sumac extract; apparent viscosity; rheology; activation energy.

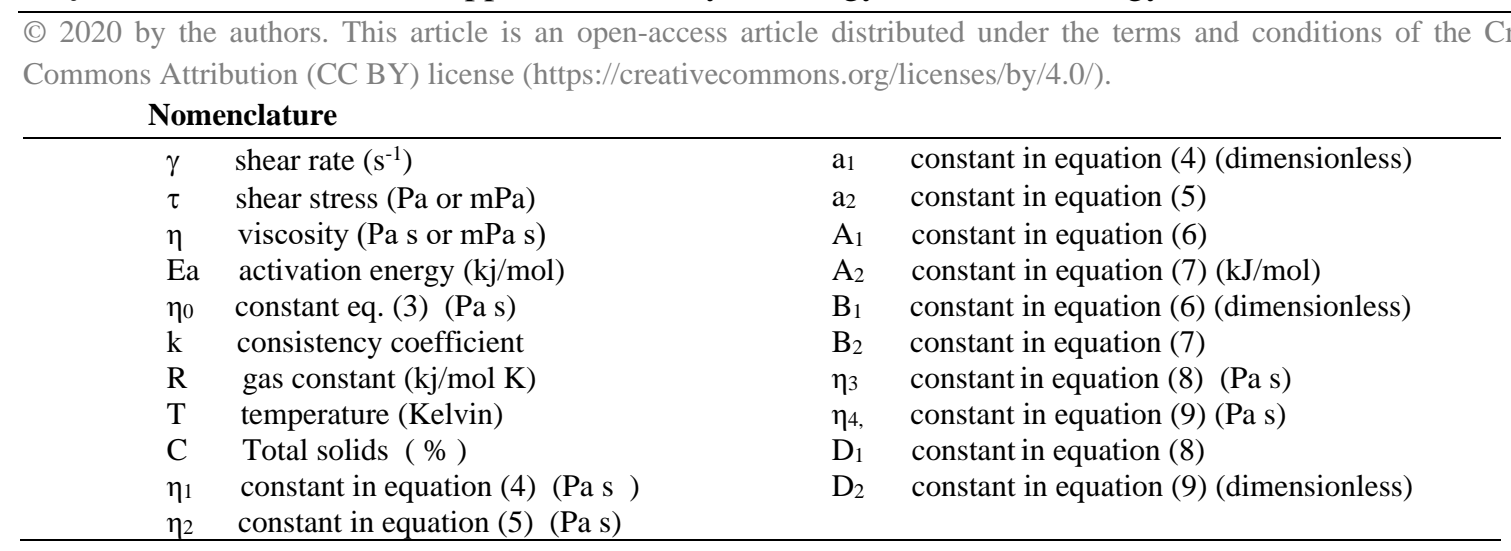

\section{Introduction}

Sumac (Rhus coriaria L.), which belongs to the Anacardiaceae family, may reach a height of 3-4 m. Sumac grows in a large area extending from the Canary Islands to the Mediterranean coastline, and to Iran and Afghanistan [1].

In Turkey, Sumac is grown in the Mediterranean and Southeastern Anatolia regions. It is widely used as spice and sauce added to kebabs, grilled meats, salads, and soups. Sumac sauce has a sour and fruity aroma [1,3]. There are two types of sumac, Rhus coriaria L. and 
Rhus cotinus, in Turkey. A more common one, Rhus coriaria L., is used to prepare sauces and spice. Sumac extract (sumac sauce) is especially used in southern and eastern Turkey, and its market has recently developed in Turkey.

There are a few researches about some properties of sumac. Zalacain et al. [4] optimized the extraction of gallotannins from sumac. Nasar-Abbas and Halkman (2004) reported that sumac has an antimicrobial effect on some strains of bacteria. Bayram et al. [5] studied flavor compounds of sumac, which was produced by the spray drying technique. Bozkurt (2006) studied the effect of sumac extract on Turkish dry-fermented meat products. Ozkanli and Tekin [6] examined the rheological properties of sumac extract according to temperature and concentration, but the research was limited to this.

Understanding the rheological properties of liquid food is necessary for quality control and sensory evaluation, as well as engineering applications that design industrial plants. Such engineering applications require that the effect of concentration and temperature on the rheological behaviors must be known for comprehending unit operations such as heat transfer and evaporation [7-17].

There are two types of pressure loss in the design of duct systems. These are major and minor losses. Minor losses are caused by changes in pipe geometries and fitted components such as sudden or gradual flow expansion and contraction, entrance and exit of tanks, elbows, bends, fittings, valves, etc. These parts of piping systems interrupt the smooth flow and cause pressure losses because of flow separation and friction.

Xia and Sun [18] reviewed the application of CFD in food processing industries, including drying, mixing, refrigeration, and sterilization. They discussed the advantages of CFD and outlined the future of CFD applications. Gut and et al. [19] studied the pressure drop of pineapple juice in a plate heat exchanger (PHE) with $50^{\circ}$ chevron plates. They determined the rheological behavior of pineapple juice at different temperatures and concentrations. The Ostwald-de Waele model accounted for the flow properties of pineapple juice. The friction factor for the non-isothermal flow of pineapple juice in the PHE was acquired for diagonal and parallel/side flow. Gratao et al. [20] experimentally studied Laminar axial flow of a pseudoplastic liquid food in annular ducts. The rheological behavior of soursop juice was determined, and then pressure loss in annular regions was measured. Huang et al. [21] investigated the rheological properties produced from inward sudden and outward expansion geometries. Some other studies about sudden expansions, contraction, and elbows are those conducted by Delhaye [22], Guglielmini et al. [23], Nathan et al. [24], Langrish et al. [25], Guo et al. [26], Tsai et al. [27], Ahmed et al. [28].

The aim of this work was to ascertain the effect of concentration and temperature on viscosity, in order to characterize the rheological properties of sumac extract and numerical investigation of some minor losses of piping systems with variable viscosity depending on temperature and concentration. Two different temperatures and concentrations are selected for the numerical part of the study.

\section{Materials and Methods}

\subsection{Materials.}

Concentrated sumac extract $(65.13 \%$ total solid) was obtained from a local manufacturer. The concentrated sumac extract was diluted with pure water to acquire different sumac extract concentrations. 


\subsection{Analytical methods.}

A $\mathrm{pH}$ meter (Inolab, Germany) was used to determine the $\mathrm{pH}$ value. The total acidity was found using $0.1 \mathrm{~N} \mathrm{NaOH}$ (until $\mathrm{pH}$ 8.1). The specific gravity of the sumac extracts was found using a refractometer (Mettler T. RE50, Switzerland) at $20{ }^{\circ} \mathrm{C}$. Protein value was analyzed by the Kjeldahl method performed according to the AOAC method [29,30]. Total solids (concentration) were found by the oven drying method [31]. The composition of concentrated sumac extract was given in Table 1.

\subsection{Rheological measurements.}

The viscosity of Sumac extracts was determined at 10, 20, 30, 40, and $50{ }^{\circ} \mathrm{C}$ using a Brookfield viscometer (Model RDVD-II, USA). All the measurements were done using spindle (LV 1) at six different speeds $(2.5,5,10,20,40$, and $80 \mathrm{rpm})$. The thermostatic water bath was used to adjust the temperature, and three measurements were performed for each sample at 30 s intervals. Shear rate $(\gamma)$ was calculated according to user's instructions as follow:

$$
\gamma=N \times 0.220
$$

Shear stress $(\tau)$ was obtained using equation (2):

$$
\tau=\eta \times \gamma
$$

where $\eta$ is the viscosity, $\gamma$ is the shear rate and $\tau$ is the shear stress.

\subsection{Statistical analysis.}

The parameters of models were calculated by the non-linear regression procedure using Sigma Plot (Sigma-Plot 11.0 version, USA). Variance analysis was performed to determine the effect of concentration and temperature on the viscosity of sumac extract using SPSS statistics software version 18.0 (Chicago, USA). Further, parameters of Eq. $(11,12)$ was estimated by the multiple regression analysis (SPSS 18.0 software).

\subsection{Numerical analysis.}

The numerical analysis was performed in steady-state conditions. The CFD code ANSYS Fluent 15.1 was employed in order to solve the governing equations using the control volume approach. Two-dimensional piping geometries were used to study the piping system by solving the momentum and energy equations. Velocity, pressure, vorticity, and kinetic energy distributions were also given for investigating the flow properties with variable viscosity. The accuracy of calculation results for the mesh structure was controlled, and the virtually grid-independent results were obtained for the selection of optimum grid numbers. The velocity inlet and pressure outlet were applied as initial conditions. No-slip condition and zero heat flux were assumed as boundary conditions.

The conservation of mass and momentum equations for steady, isothermal and incompressible flow can be written as:

$$
\begin{gathered}
\frac{\partial \mathrm{U}_{\mathrm{i}}}{\partial \mathrm{x}_{\mathrm{i}}}=0 \\
\mathrm{U}_{\mathrm{j}} \frac{\partial \mathrm{U}_{\mathrm{i}}}{\partial \mathrm{x}_{\mathrm{j}}}=-\frac{1}{\rho} \frac{\partial \mathrm{p}}{\partial \mathrm{x}_{\mathrm{i}}}+\frac{\partial}{\partial \mathrm{x}_{\mathrm{j}}}\left(\mathrm{v}\left(\frac{\partial \mathrm{U}_{\mathrm{i}}}{\partial \mathrm{x}_{\mathrm{j}}}+\frac{\partial \mathrm{U}_{\mathrm{j}}}{\partial \mathrm{x}_{\mathrm{i}}}\right)\right.
\end{gathered}
$$

A grid independence study was carried out with the comparison of maximum velocity. The comparisons for both sudden expansion and elbow geometries are given in Table 7. Based 
on the optimum performance in terms of accuracy, 14800 and 21300 quadrilateral elements were selected for the individual geometries. Validation was carried out with an analytical equation in laminar flow in the pipe. In order to validate the simulation, the results were compared with analytical equation 5.

Laminar flow in pipes:

$$
u_{(r)}=2 V_{\text {avg }}\left(1-\frac{r^{2}}{R^{2}}\right)
$$

The velocity profile of the CFD and analytical solution results in laminar pipe flow is shown in Figure 1.

a) Sudden expansion

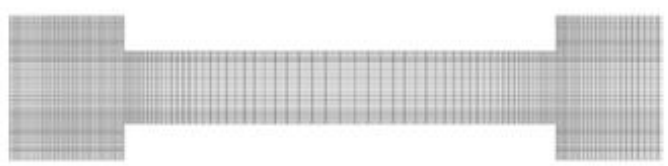

b) $90^{\circ}$ Elbow

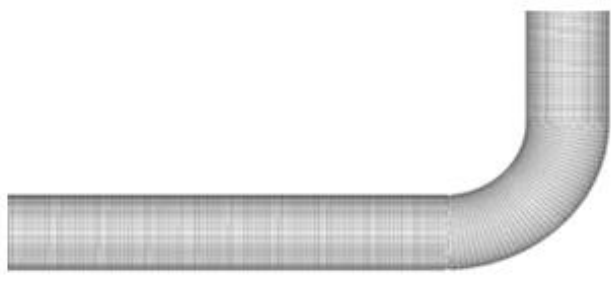

Figure 1. Meshed geometry.

\section{Results and Discussion}

\subsection{Physicochemical properties (65.13\% total solids concentration).}

Some physicochemical properties of the sample are given in Table 1. Total dry matter, protein, density, acidity, and $\mathrm{pH}$ values of the sample were determined as $65.13 \%, 3.79 \%$, $1.2678 \mathrm{~g} / \mathrm{cm} 3,6060$ milliequivalents $(\mathrm{me}) / \mathrm{L}$, and 1.75 , respectively. It is seen that the $\mathrm{pH}$ value of the sample is low, and its acidity is high. The low $\mathrm{pH}$ and high acidity values prevent the presence and development of microorganisms. These are important as they influence food viscosity and shelf life [32]. Ozkanlı and Tekin [6] determined the $\mathrm{pH}$ value of the concentrated sumac as 3.2, while Bozdogan [33] found the acidity and $\mathrm{pH}$ of bitter orange juice concentrate as $6094 \mathrm{me} / \mathrm{L}$ and 1.75 , respectively.

Table 1. Compositional data of concentrated sumac extract.

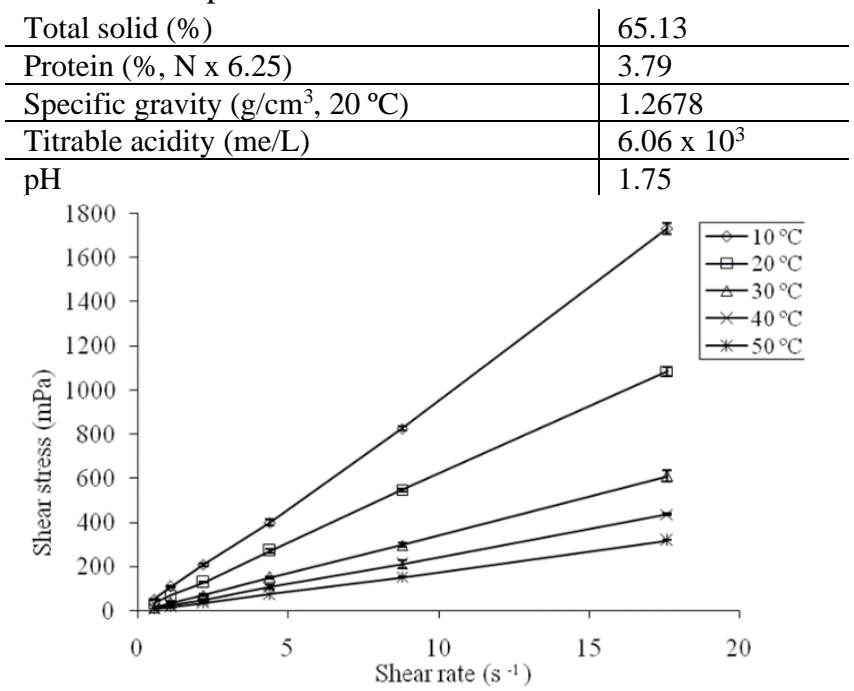

Figure 2. The relationship between shear rate and shear stress for concentrated sumac extract $(65.13 \%$ total solids concentration). 


\subsection{Rheological behavior.}

The rheological properties of sumac extract were examined at a concentration of $65.13 \%, 60.32 \%, 55.53 \%, 50.44 \%$ and, $45.65 \%$ of total solids and at temperatures in the range of $10-50^{\circ} \mathrm{C}$. Figure 2 shows the flow diagram for the concentrated sumac extract. The shear stress versus the shear rate value gave a linear relationship. Thus, all samples displayed Newtonian behavior. The experimental results were fitted to the Newtonian equation (eq.2) $[6,34,35,36,37]$. Similar results were acquired for diluted samples of sumac extract. The viscosity values were calculated from the Newtonian model for concentrations and temperatures (Table 2). As shown in Table 2, the viscosity of the sumac extracts decreased with a rise in concentration and temperature.

\subsubsection{The effect of temperature.}

The effect of temperature on the flow properties of foods can be explained by the Arrhenius model [38-42].

$$
\eta=\eta o \exp (E a / R T)
$$

where Ea is the activation energy, $\eta_{0}$ is a constant, $\mathrm{T}$ is the temperature and $\mathrm{R}$ is the gas constant. The activation energy values calculated from the slope of the linear relationship of $\ln (\eta)$ versus $(1 / \mathrm{T})$ are given in Table 3. As can be observed in Table 3, Ea values changed in the range of 11.16-34.35 kJ/mol for all concentrations of sumac extracts. These values are consistent with the values reported by other authors for clarified fruit juices [34,43]. Furthermore, lower extract concentrations gave higher $\eta_{0}$ values. The correlation coefficient $\left(\mathrm{r}^{2}\right)$ values for this modeling were higher than 0.8642 . Results have displayed that temperature has a significant effect $(p<0.01)$ on the flow behavior of the sumac extract.

Table 2. Viscosities of sumac extracts at different temperatures and concentrations.

\begin{tabular}{l|c|c|c} 
Concentration & $\mathrm{T}\left({ }^{\circ} \mathrm{C}\right)$ & Newtonian model & \\
\hline (\% total solid) & & $\eta(\mathrm{mPa} \mathrm{s})$ & $\mathrm{r}^{2}$ \\
\hline 65.13 & 10 & $95.88 \pm 2.86$ & 0.9991 \\
\hline & 20 & $61.85 \pm 0.49$ & 0.9999 \\
\hline & 30 & $32.96 \pm 0.53$ & 0.9999 \\
\hline & 40 & $22.84 \pm 0.76$ & 0.9997 \\
\hline 60.32 & 50 & $16.56 \pm 0.03$ & 0.9997 \\
\hline & 10 & $47.38 \pm 0.69$ & 0.9997 \\
\hline & 20 & $29.26 \pm 0.02$ & 0.9999 \\
\hline & 30 & $19.09 \pm 0.28$ & 0.9998 \\
\hline 55.53 & 40 & $13.98 \pm 0.23$ & 0.9993 \\
\hline & 50 & $11.12 \pm 1.03$ & 0.9981 \\
\hline & 10 & $26.30 \pm 0.37$ & 0.9986 \\
\hline & 20 & $16.18 \pm 0.14$ & 0.9991 \\
\hline 50.44 & 30 & $10.85 \pm 0.49$ & 0.9957 \\
\hline & 40 & $9.68 \pm 0.22$ & 0.9981 \\
\hline & 50 & $7.85 \pm 0.03$ & 0.9960 \\
\hline & 10 & $15.14 \pm 0.41$ & 0.9994 \\
\hline & 20 & $10.98 \pm 0.39$ & 0.9946 \\
\hline & 30 & $8.38 \pm 0.26$ & 0.9976 \\
\hline & 40 & $6.42 \pm 0.32$ & 0.9883 \\
\hline & 50 & $6.29 \pm 0.03$ & 0.9922 \\
\hline & 10 & $9.68 \pm 0.27$ & 0.9905 \\
\hline & 20 & $8.13 \pm 0.20$ & 0.9893 \\
\hline & 30 & $6.13 \pm 0.18$ & 0.9853 \\
\hline & 40 & $5.38 \pm 0.06$ & 0.9897 \\
\hline & 50 & $5.77 \pm 0.06$ & 0.9993
\end{tabular}


Table 3. Activation energies of sumac extracts.

\begin{tabular}{l|l|l|l}
$\begin{array}{c}\text { Concentration } \\
(\% \text { total solid })\end{array}$ & $\eta_{0}(\mathrm{mPas})$ & Ea $(\mathrm{kJ} / \mathrm{mol})$ & $\mathrm{r}^{2}$ \\
\hline 65.13 & $4.34 \times 10^{-5}$ & $34.35 \pm 1.87$ & 0.9912 \\
\hline 60.32 & $3.33 \times 10^{-4}$ & $27.78 \pm 1.69$ & 0.9890 \\
\hline 55.53 & $1.6 \times 10^{-3}$ & $22.47 \pm 2.88$ & 0.9529 \\
\hline 50.44 & $8.18 \times 10^{-3}$ & $17,58 \pm 2.1$ & 0.9591 \\
\hline 45.65 & $8.06 \times 10^{-2}$ & $11.16 \pm 2.50$ & 0.8642
\end{tabular}

\subsubsection{The effect of concentration.}

The effect of the concentration on the viscosity is given in Figure 3. The viscosity rose linearly with sumac extract concentration at all temperatures. Furthermore, the effect of concentration on the viscosity of sumac extract was found to be significant $(\mathrm{P}<0.01)$.

The change in viscosity with concentration was explained by Power law and Exponential type model, (Eq 4) and (Eq 5) [44].

$$
\begin{aligned}
& \eta=\eta_{1} C^{a_{1}} \\
& \eta=\eta_{2} \exp (a 2 C)
\end{aligned}
$$

In this case, $\mathrm{C}$ stands for the concentration ( $\%$ total solid), whereas $\eta_{1}, \eta_{2}$, a1, and a represent the constants. The values of viscosity from Table 2 were fitted into Eq. (7) and Eq. (8) to calculate $\eta_{1}, \eta_{2}, a_{1}$, and a2, and presented in Table 4 . The correlation coefficients $(0.9657)$ for the Exponential model were higher than the Power law (0.9459). These values indicated that the Exponential model seems to define well the effect of concentration on the viscosity of sumac extract.

Activation energy depends upon concentration at a constant temperature. The change of activation energy with concentration can be defined by several models [35,45]. Two models (Power law (Eq. 9) and Exponential model (Eq. 10)) were used in this study:

$$
\begin{aligned}
& E a=A_{1} C^{B 1} \\
& E a=A_{2} \exp \left(B_{2} C\right)
\end{aligned}
$$

Where Ea is the activation energy, $\mathrm{C}$ is the concentration (\% total solids), and $\mathrm{A}_{1}, \mathrm{~A}_{2}$, $\mathrm{B}_{1}$, and $\mathrm{B}_{2}$ are constants. The relationship between $\mathrm{Ea}$ and $\mathrm{C}$ values was assessed by fitting the experimental data with the Exponential and Power-law models. The parameters estimated for these models are presented in Table 5. As can be seen in Table 5, the best fit was acquired for the Power-law relationship as in Eq (9).

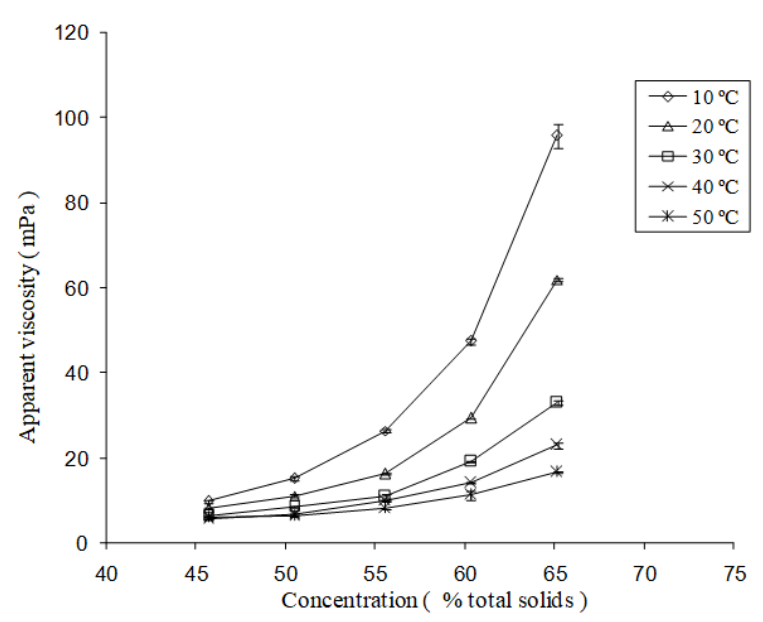

Figure 3. The relationship between viscosity and concentration for sumac extracts. 
Table 4. Effect of concentration on the viscosity of sumac extract at different temperatures.

\begin{tabular}{l|l|l|l|l|l|l} 
& \multicolumn{3}{|c}{ Power-law model: $\eta=\eta_{1} \mathrm{C}^{\mathrm{a}}$} & \multicolumn{3}{c}{ Exponential model: $\eta=\eta_{2} \exp (\mathrm{bC})$} \\
\hline $\mathrm{T}\left({ }^{\circ} \mathrm{C}\right)$ & $\eta_{1}$ (mPas) & $\mathrm{A}$ & $\mathrm{r}^{2}$ & $\eta_{2}(\mathrm{mPas})$ & $\mathrm{b}$ & $\mathrm{r}^{2}$ \\
\hline 10 & $4.25 \times 10^{-13}$ & $7.91 \pm 0.61$ & 0.9915 & $1.65 \times 10^{-2}$ & $0.13 \pm 0.06$ & 0.9964 \\
\hline 20 & $4.12 \times 10^{-13}$ & $7.81 \pm 0.98$ & 0.9766 & $1.14 \times 10^{-2}$ & $0.13 \pm 0.01$ & 0.9857 \\
\hline 30 & $2.64 \times 10^{-9}$ & $5.55 \pm 0.68$ & 0.9736 & $4.59 \times 10^{-2}$ & $0.1 \pm 0.009$ & 0.9862 \\
\hline 40 & $7.96 \times 10^{-8}$ & $4.65 \pm 0.52$ & 0.9755 & $9.15 \times 10^{-2}$ & $0.08 \pm 0.006$ & 0.9882 \\
\hline 50 & $4.54 \times 10^{-6}$ & $3.61 \pm 0.55$ & 0.9459 & $2.53 \times 10^{-1}$ & $0.06 \pm 0.007$ & 0.9657
\end{tabular}

Table 5. Effect of concentrations on the activation energy of the flow.

\begin{tabular}{l|l|l|l|l} 
Model & $\mathrm{i}$ & $\mathrm{Ai}$ & $\mathrm{Bi}$ & $\mathrm{r}^{2}$ \\
\hline Power law: $\mathrm{Ea}=\mathrm{A}_{1} \mathrm{C}^{\mathrm{B} 1}$ & 1 & $2.14 \times 10^{-4}$ & $2.87 \pm 0.18$ & 0.9910 \\
\hline Exponential: Ea: $\mathrm{A}_{2} \exp \left(\mathrm{B}_{2} \mathrm{C}\right)$ & 2 & $1.29 \pm 0.34$ & $5.06 \times 10^{-2}$ & 0.9816
\end{tabular}

\subsubsection{Combined effects of temperature and concentration.}

In the process applications, it is significant to acquire a simple equation describing the combined effect of concentration and temperature on sumac extract. Equations (11) and (12) were used to assess the viscosity of sumac extract for the temperatures and concentrations studied.

$$
\begin{aligned}
& \eta=\eta_{3} \exp \left(D{ }_{1} C+E a / R T\right) \\
& \eta=\eta_{4} C^{D 2} \exp (E a / R T)
\end{aligned}
$$

where $\mathrm{C}$ is the concentration ( $\%$ total solids) and $\eta_{3}, \eta_{4}, \mathrm{D}_{1}$, and $\mathrm{D}_{2}$ are constants. The equation was linearized to acquire the parameters given below. The values of the constants are presented in Table 6.

Table 6. Combined effects of temperature and concentration on viscosity.

\begin{tabular}{c|c|c|c|c|c|c} 
Equation & $\mathrm{I}$ & $\eta_{\mathrm{i}}$ & $\mathrm{j}$ & $\mathrm{D}_{\mathrm{j}}$ & $\mathrm{Ea}\left(\mathrm{kJ} \mathrm{mol}^{-1}\right)$ & $\mathrm{r}^{2}$ \\
\hline 8 & 3 & $1.39 \times 10^{-5}$ & 1 & $0.087 \pm 0.006$ & $22.66 \pm 2.18$ & 0.9372 \\
\hline 9 & 4 & $1.02 \times 10^{-11}$ & 2 & $4.73 \pm 0.35$ & $22.66 \pm 2.37$ & 0.9255
\end{tabular}

As can be seen from Table 6, Eq.(11) explained the combined effect of concentration and temperature adequately. We proposed a model to describe the viscosity of sumac extract as below:

$$
\eta=1.39 \times 10^{-5} \exp (0.087 C+2726 / T)
$$

\subsection{Numerical results.}

Figures 6-9 show the a) velocity vectors b) velocity magnitude c) streamlines d) vorticity contours e) pressure distributions f) kinetic energy distributions for sudden expansion case with different fluid temperatures and concentrations. Two different temperatures and concentrations were selected to examine the effect of variable viscosity, which depends on temperature and concentration. Firstly, the fluid temperature of $10^{\circ} \mathrm{C}$ and fluid concentration of $45.65 \%$ is given in Fig. 4. Then the fluid temperature of $10^{\circ} \mathrm{C}$ and fluid concentration of $65.13 \%$ is given in Fig.5. Also, the fluid temperature of $50^{\circ} \mathrm{C}$ and the fluid concentration of $45.65 \%$, as well as the fluid temperature of $50^{\circ} \mathrm{C}$ and the fluid concentration of $65.13 \%$, are given respectively in Figures 6 and 7. Streamlines show the recirculating flow zone with eddies that occur near the wall of the larger section of pipe for all the cases. These turbulent eddies result in a loss of total energy. The recirculation length is minimum, and the pressure difference between the narrow and larger section of pipe is maximum in the cases when the fluid temperature is $10^{\circ} \mathrm{C}$, and fluid concentration is $65.13 \%$. When the vorticity contours are 
examined, it is seen that the vorticity values appear close to the wall of the pipe with a larger diameter. However, vorticity levels are zero in this region for other cases. The maximum velocity values are concentrated in the narrow section of the pipe for each case, whereas at 50 degrees and $45.65 \%$ concentration, maximum velocity values are formed towards the expansion section of the pipe because of the lower viscosity, and the shear stress, accordingly. Due to the higher viscosity, the pressure loss is high for a concentration of 10 degrees and $65.13 \%$ concentration, and a rapid decrease of velocity in the cross-section expansion occurs. Inlet velocity of $0.1 \mathrm{~m} / \mathrm{s}$ increased to $0.26 \mathrm{~m} / \mathrm{s}$ in the contraction section for all cases. Pressure value in the inlet section was approximately $350 \mathrm{~Pa}$ and decreased to approximately $40 \mathrm{~Pa}$ for the cases with the values of $10^{\circ} \mathrm{C}$ and $45.63 \%$. Negative pressure values are seen in the expansion section for all other cases.

Table 7. Grid independence study

\begin{tabular}{l|l|l} 
Sumac velocity inlet $(\mathrm{m} / \mathrm{s})$ & Number of elements & Maximum velocity $(\mathrm{m} / \mathrm{s})$ \\
\hline sudden expansion & & \\
\hline 0.1 & 3700 & 0,2942 \\
\hline & 7400 & 0,2993 \\
\hline & 14800 & 0,2998 \\
\hline & 29600 & 0,3 \\
\hline Elbow & & \\
\hline 0.1 & 6940 & 0,1514 \\
\hline & 14120 & 0,152 \\
\hline & 21300 & 0,1521 \\
\hline & 28560 & 0,1521
\end{tabular}

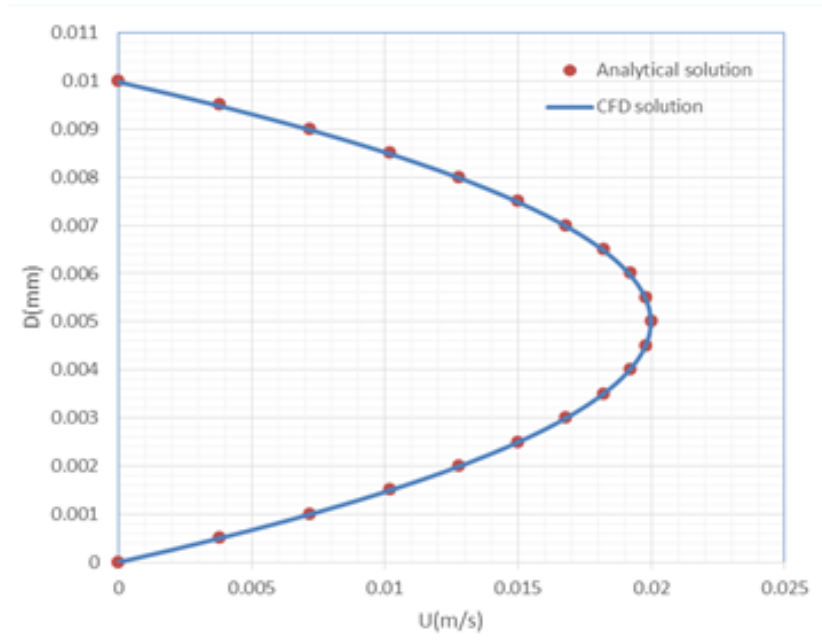

Figure 4. Velocity profile of CFD and analytical solution results in laminar pipe flow.

Figures 9-12 show the a) velocity vectors b) velocity magnitude c) streamlines d) vorticity contours e) pressure distributions f) kinetic energy distributions for $90^{\circ}$ bend case with temperatures of $10^{\circ} \mathrm{C}$ and $50^{\circ} \mathrm{C}$, and concentrations of $45.63 \%$ and $65.13 \%$. When the fluid moves inside the bend, maximum velocity with the value of $0.15 \mathrm{~m} / \mathrm{s}$ tends to occur towards the curvature section of the bend for the case of the fluid temperature of $50^{\circ} \mathrm{C}$ and fluid concentration of $65.13 \%$. As the flow enters the pipe bend, the pressure decreases gradually from the curvature of bend to the exit of the bend for the case of $50^{\circ} \mathrm{C}$ fluid temperature and $65.13 \%$ fluid concentration. In contrast to this case, the pressure increases on the outer wall of the bend due to the curvature of the bend for other cases. Dashed lines show negative pressure values. 

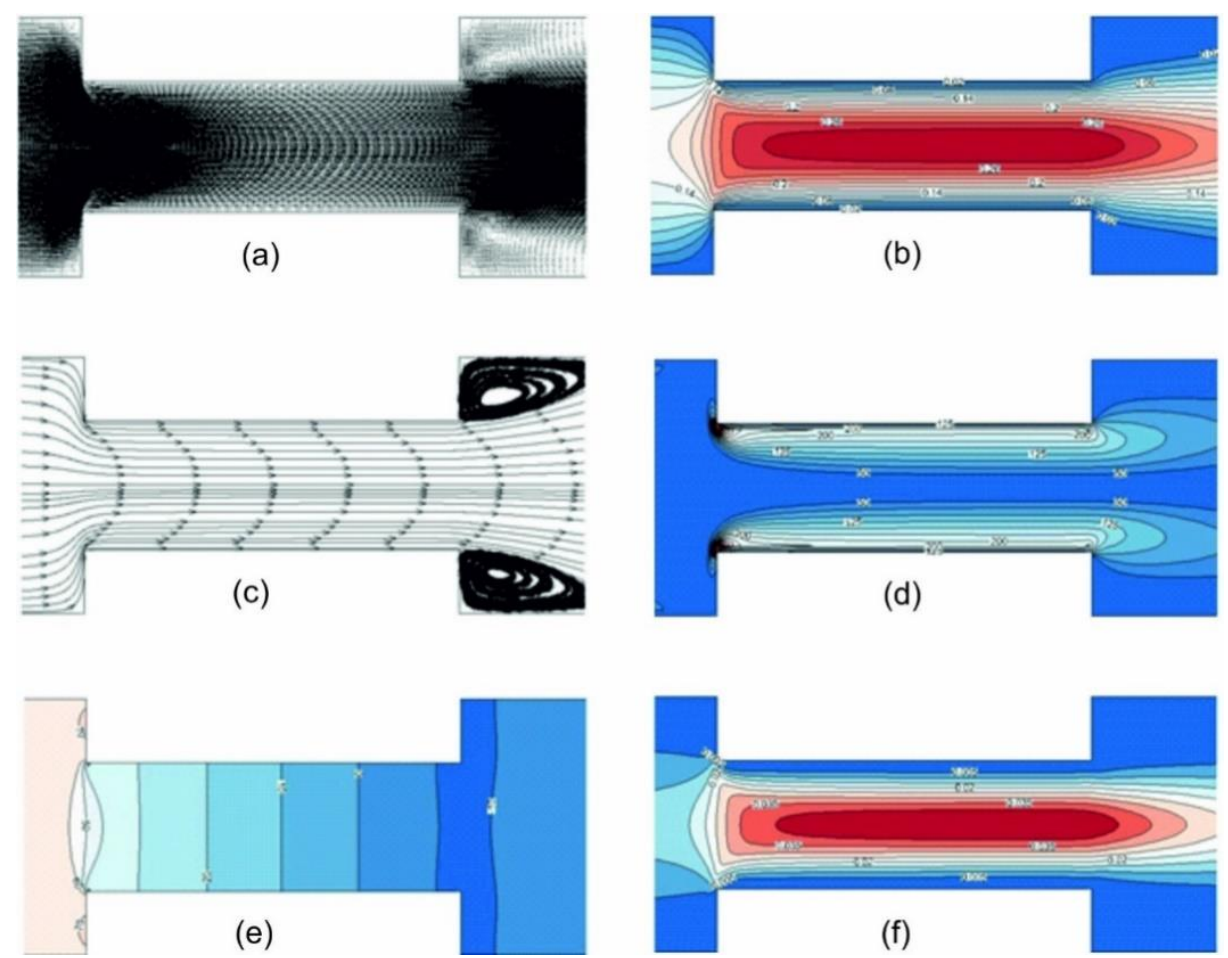

Figure 5. a) Velocity vectors b) Velocity magnitude c) Stream Lines d) Vorticity contours e) Pressure Distributions f) Kinetic Energy Distributions for the case of a fluid temperature of $10^{\circ} \mathrm{C}$ and fluid concentration of $45.65 \%$.
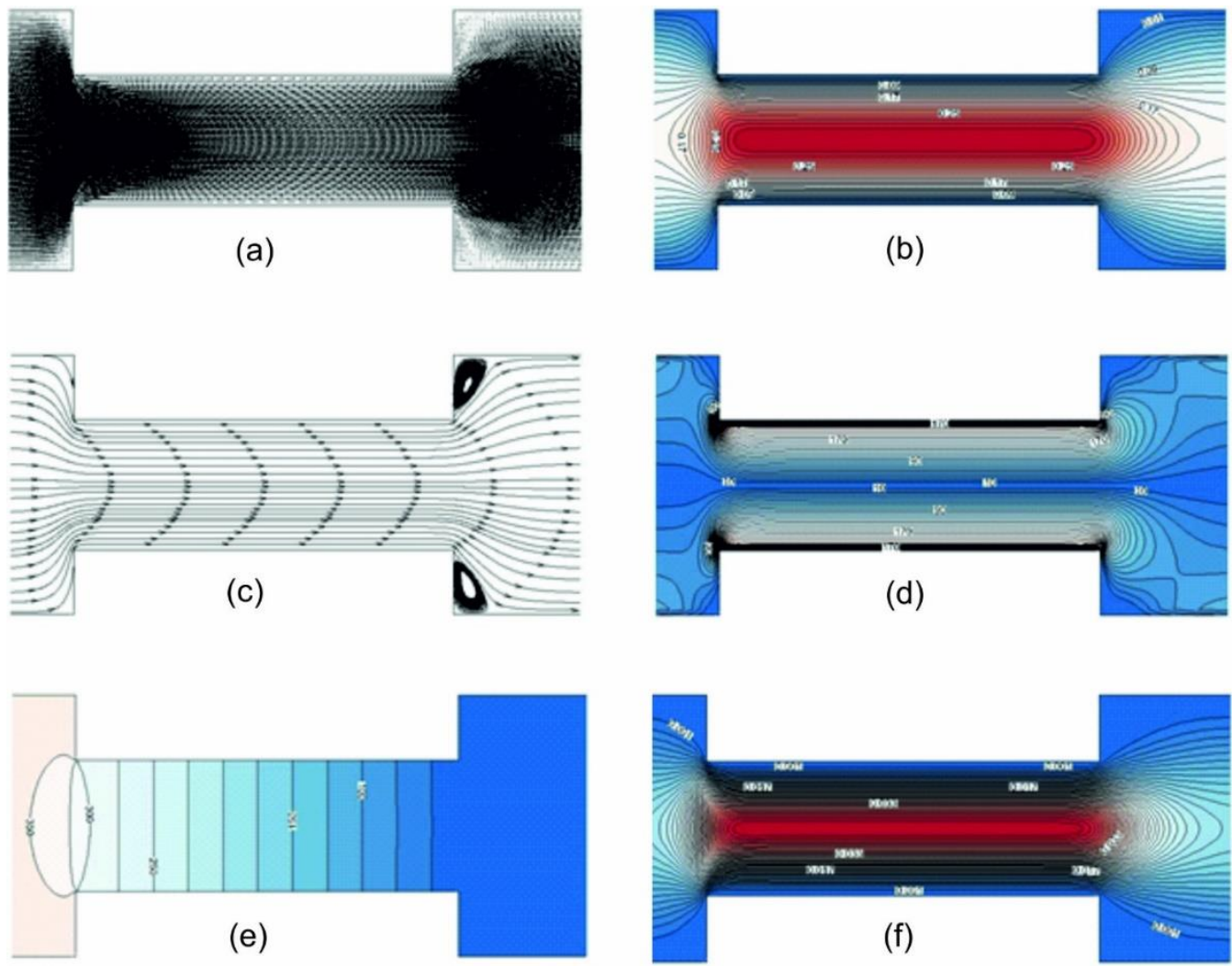

Figure 6. a) Velocity vectors b) Velocity magnitude c) Stream Lines d) Vorticity contours e) Pressure Distributions f) Kinetic Energy Distributions for the case of a fluid temperature of $10^{\circ} \mathrm{C}$ and fluid concentration of $65.13 \%$. 

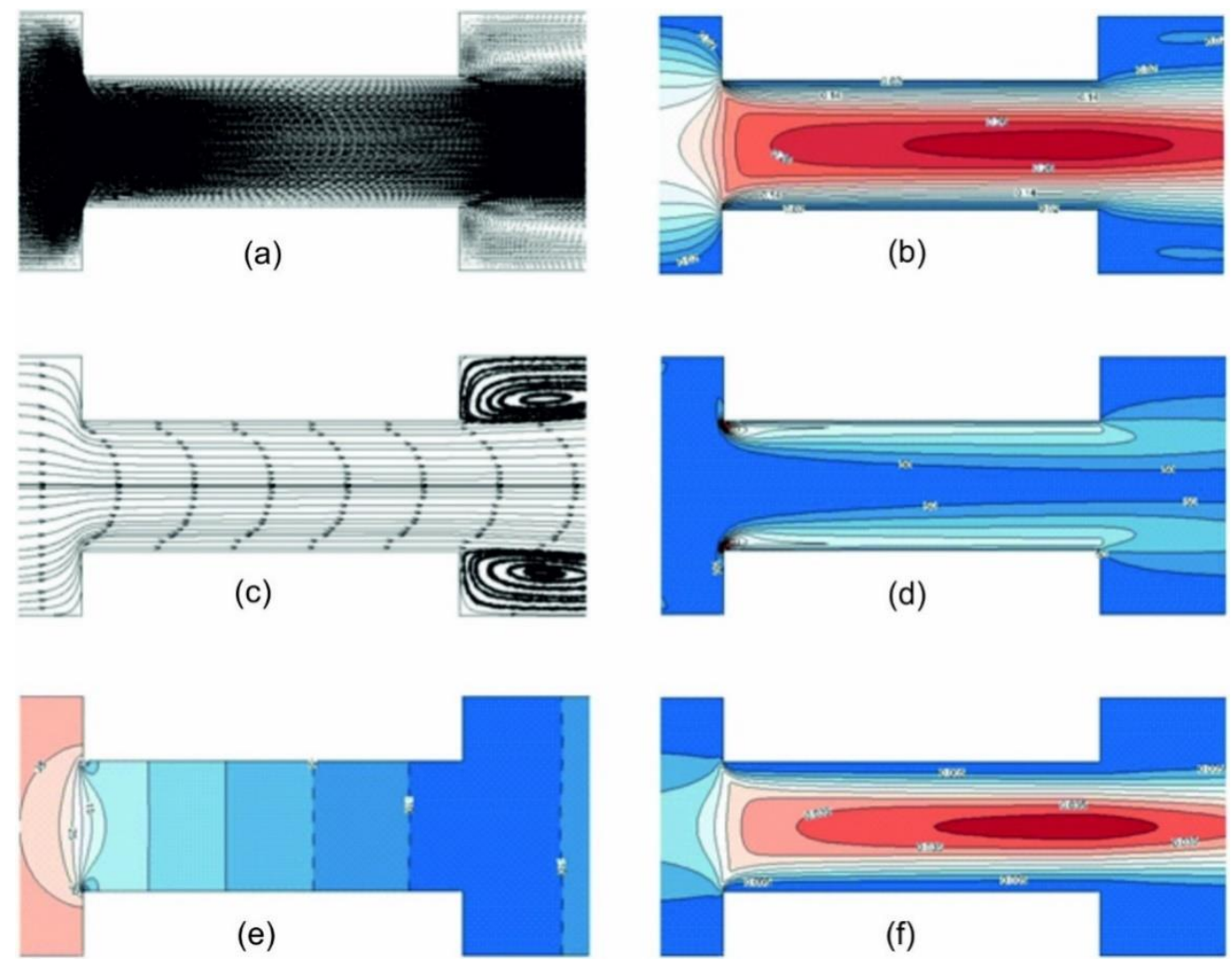

Figure 7. a) Velocity vectors b) Velocity magnitude c) Stream Lines d) Vorticity contours e) Pressure

Distributions f) Kinetic Energy Distributions for the case of a fluid temperature of $50^{\circ} \mathrm{C}$ and fluid concentration of $45.65 \%$.
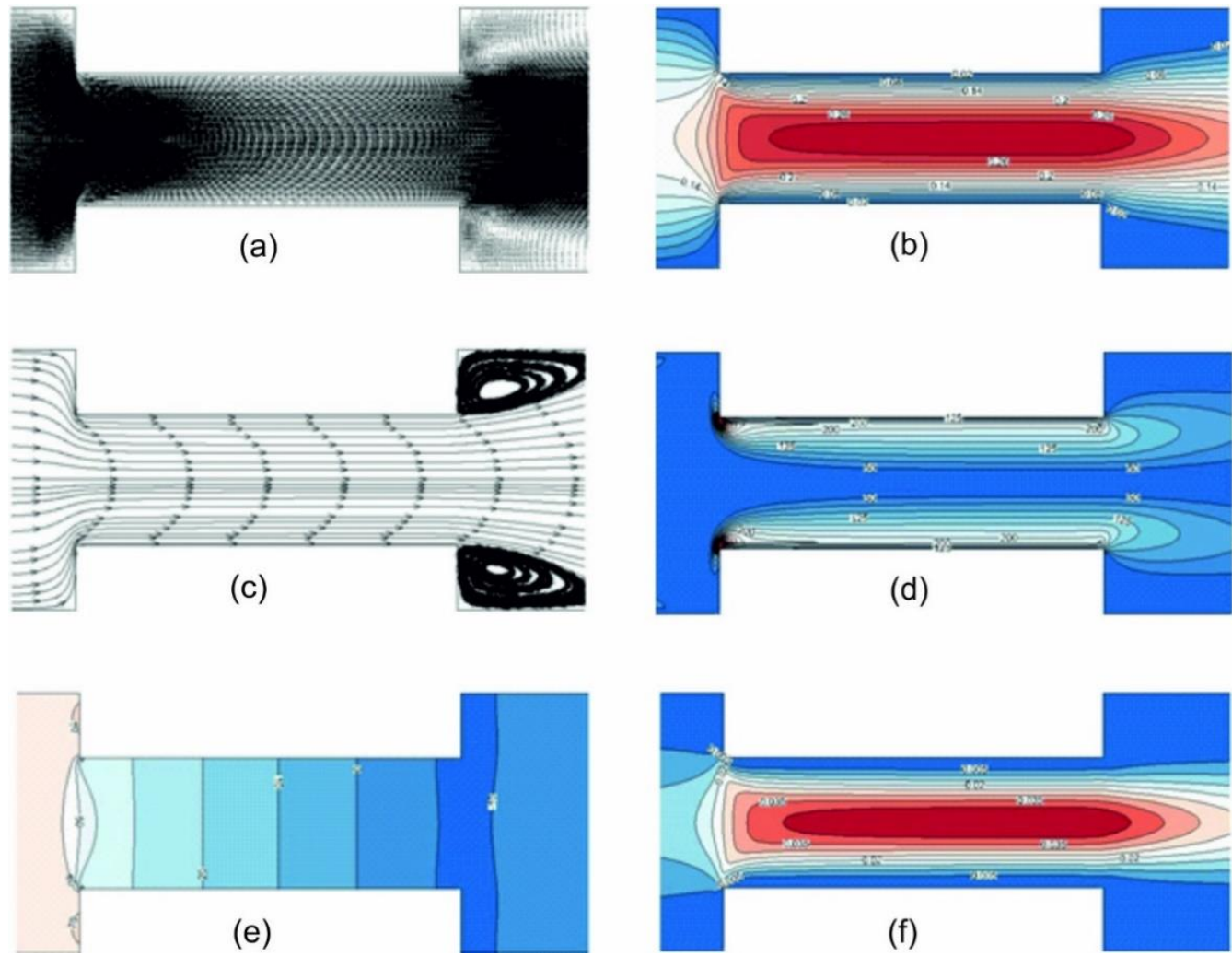

Figure 8. a) Velocity vectors b) Velocity magnitude c) Stream Lines d) Vorticity contours e) Pressure

Distributions f) Kinetic Energy Distributions for the case of a fluid temperature of $50^{\circ} \mathrm{C}$ and fluid concentration of $65.13 \%$. 

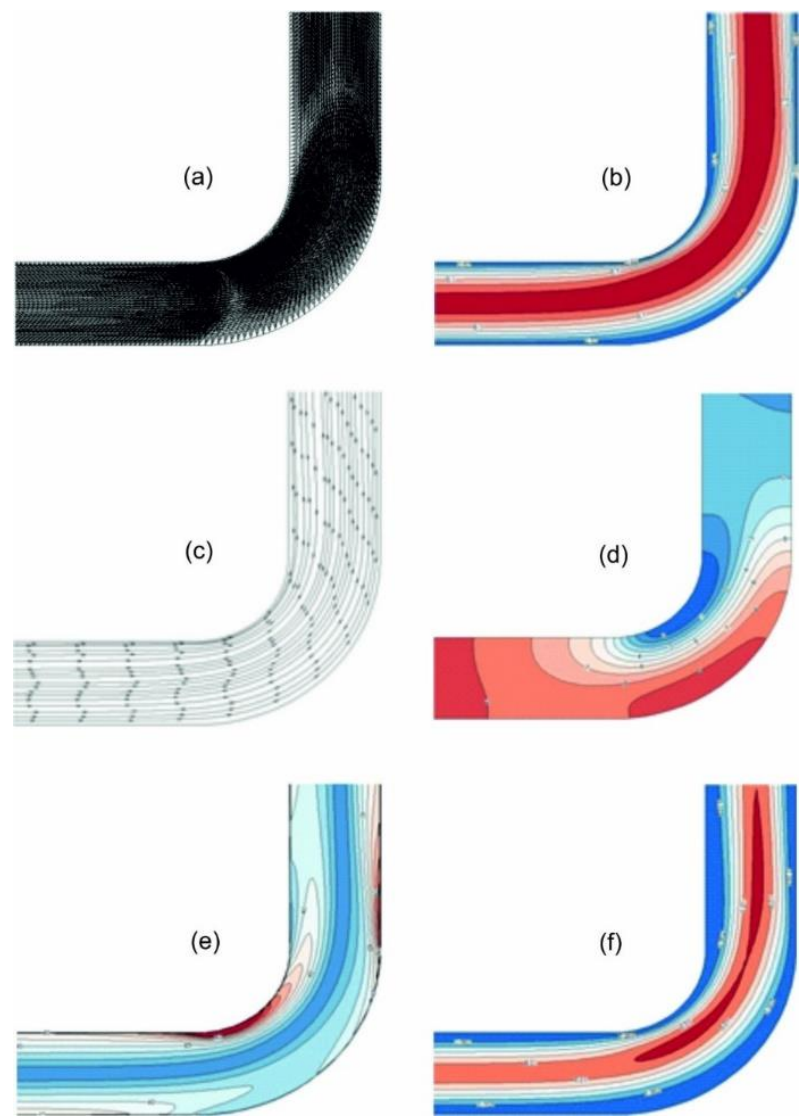

Figure 9. a) Velocity vectors b) Velocity magnitude c) Stream Lines d) Vorticity contours e) Pressure Distributions f) Kinetic Energy Distributions for the case of a fluid temperature of $10^{\circ} \mathrm{C}$ and fluid concentration of $45.65 \%$.
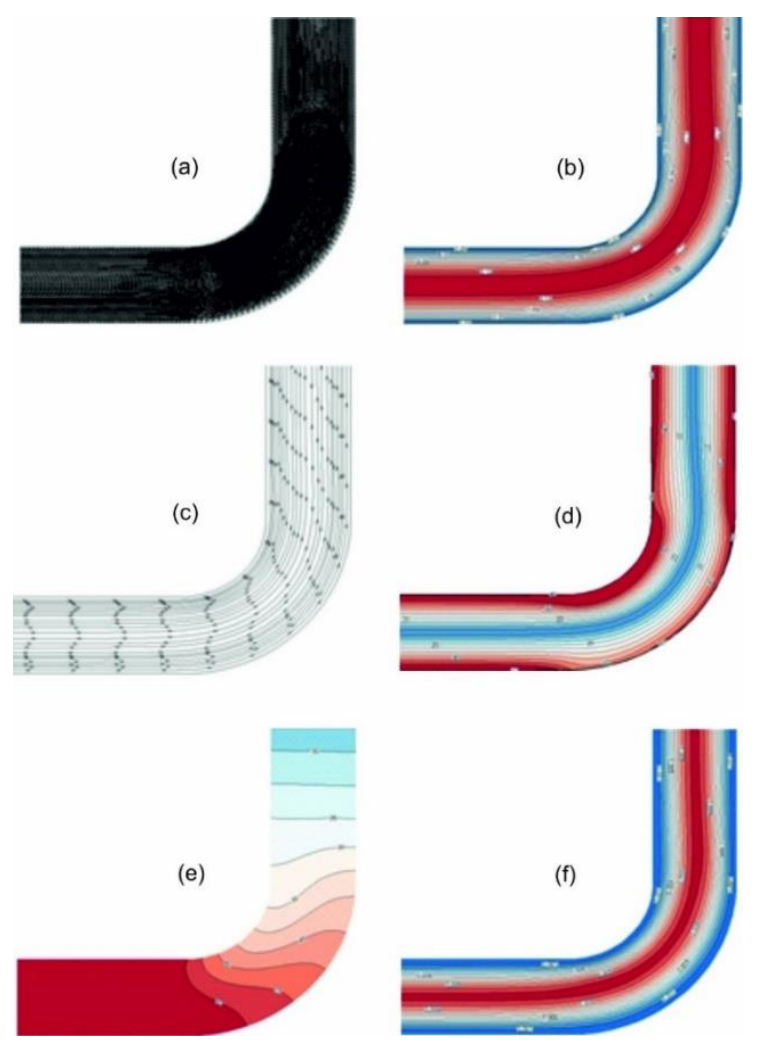

Figure 10. a) Velocity vectors b) Velocity magnitude c) Stream Lines d) Vorticity contours e) Pressure Distributions f) Kinetic Energy Distributions for the case of a fluid temperature of $10^{\circ} \mathrm{C}$ and fluid concentration of $65.13 \%$. 

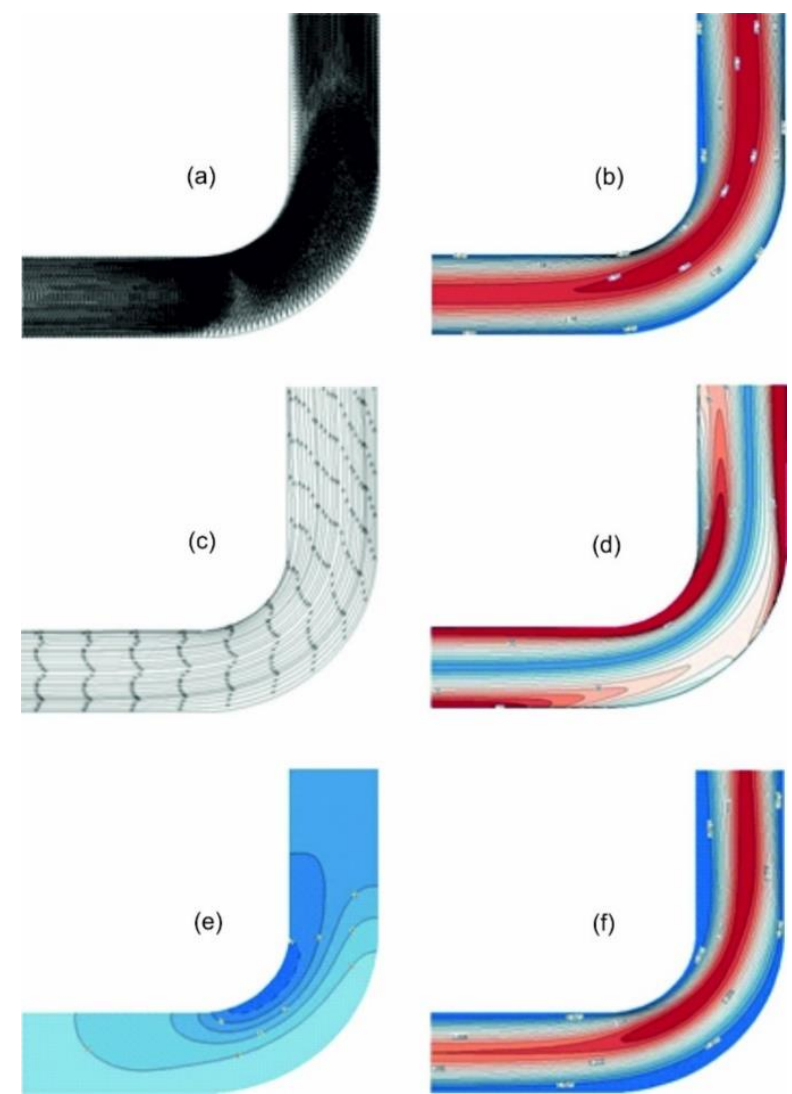

Figure 11. a) Velocity vectors b) Velocity magnitude c) Stream Lines d) Vorticity contours e) Pressure Distributions f) Kinetic Energy Distributions for the case of a fluid temperature of $50^{\circ} \mathrm{C}$ and fluid concentration of $45.65 \%$.
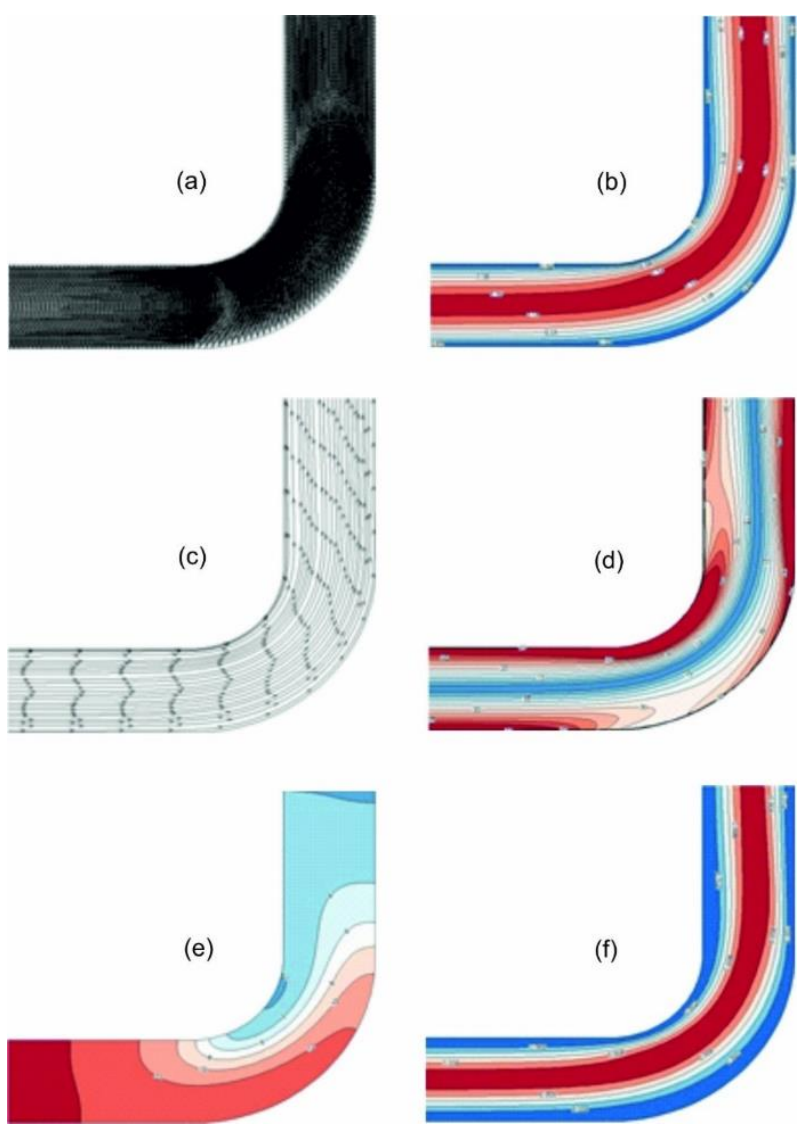

Figure 12. a) Velocity vectors b) Velocity magnitude c) Stream Lines d) Vorticity contours e) Pressure Distributions f) Kinetic Energy Distributions for the case of a fluid temperature of $50^{\circ} \mathrm{C}$ and fluid concentration of $65.13 \%$. 

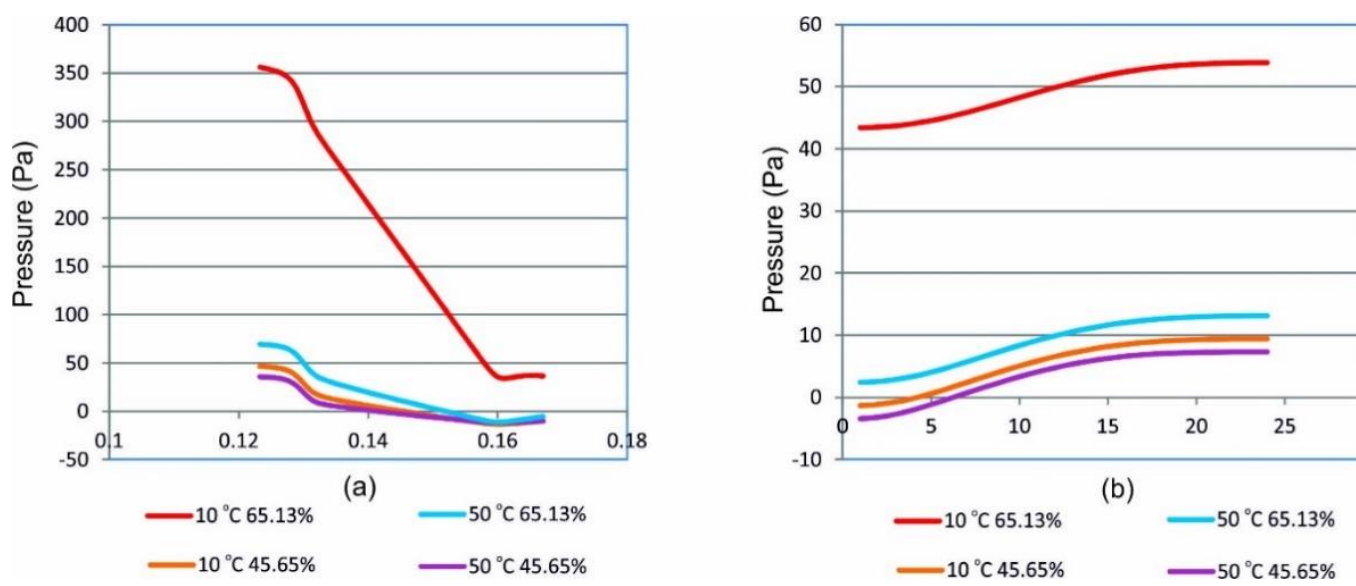

Figure 13. Pressure distribution at the sudden expansion section center along the $\mathrm{x}$-axis and (b) curvature of the bend.

Figure 13 shows the (a) pressure distribution at the sudden expansion section center along the $\mathrm{x}$-axis and (b) curvature of the bend. As shown in this figure, maximum pressure magnitudes occur for the values of $10^{\circ} \mathrm{C}$ and $65.13 \%$.

\section{Conclusions}

Sumac extracts at different concentrations $(45.65 \%-65.13 \%$ total solids) were detected to show Newtonian behavior within the temperature ranges of $10-50{ }^{\circ} \mathrm{C}$. The viscosity of sumac extracts diminished with increased temperature, as expected. The activation energy is found to rise with increased concentration. The relationship between activation energy and concentration was well explained by the Power-law model in comparison to the Exponential model. Furthermore, viscosity rose non-linearly with concentration. The effect of concentration on viscosity was best explained by the Exponential model. Due to the higher viscosity, the pressure loss is high for the temperature of $10^{\circ} \mathrm{C}$ and a concentration of $65.13 \%$, and a rapid decrease of velocity occurs in the cross-section expansion. In contrast to the concentration of $65.13 \%$ at $50^{\circ} \mathrm{C}$, the pressure increases on the outer wall of the bend due to the curvature of the bend for other cases.

\section{Funding}

This research received no external funding.

\section{Acknowledgments}

This research has no acknowledgment.

\section{Conflicts of Interest}

The authors declare no conflict of interest.

\section{References}

1. Nasar-Abbas, S.M.; Halkman, A.K. Antimicrobial effect of water extract of sumac (Rhus coriaria L.) on the growth of some food borne bacteria including pathogens. International Journal of Food Microbiology 2004, 97, 63-69, https://doi.org/10.1016/j.ijfoodmicro.2004.04.009.

2. Tiryaki, G.Y.; Çınar, I. Kahramanmaraş’ta geleneksel sumak (Rhus coriaria L.) ekşisi üretimi. Geleneksel Gidalar Sempozyumu 2004, 161-164. 
3. Bozkurt, H. Investigation of the effect of sumac extract and BHT addition on the quality of sucuk (Turkish dry-fermented sausage). Journal of the Science of Food and Agriculture 2006, 86, 849-856, https://doi.org/10.1002/jsfa.2431.

4. Zalacain, A.; Prodanov, M.; Carmona, M.; Alonso, G.L. Optimisation of Extraction and Identification of Gallotannins from Sumac Leaves. Biosystems Engineering 2003, 84, 211-216, https://doi.org/10.1016/S1537-5110(02)00246-5.

5. Bayram, Ö.A.; Bayram, M.; Tekin, A.R. Spray drying of sumac flavour using sodium chloride, sucrose, glucose and starch as carriers. Journal of Food Engineering 2005, 69, 253-260, https://doi.org/10.1016/j.jfoodeng.2004.08.012.

6. Ozkanli, O.; Tekin, A.R. Rheological Behaviors of Sumac Concentrate. International Journal of Food Properties 2008, 11, 213-222, https://doi.org/10.1080/10942910701435448.

7. Bhardwaj, M.; Singh, R.; Saxena, D.C. Rheology: A Tool to Predict Quality of Foods. In: Technologies for Value Addition in Food Products and Processes. Apple Academic Press, 2019; pp. 1-24.

8. Liu, J.; Wang, R.; Wang, X.; Yang, L.; Shan, Y.; Zhang, Q.; Ding, S. Effects of High-Pressure Homogenization on the Structural, Physical, and Rheological Properties of Lily Pulp. Foods 2019, 8, https://doi.org/10.3390/foods8100472.

9. Makroo, H.A.; Prabhakar, P.K.; Rastogi, N.K.; Srivastava, B. Characterization of mango puree based on total soluble solids and acid content: Effect on physico-chemical, rheological, thermal and ohmic heating behavior. LWT 2019, 103, 316-324, https://doi.org/10.1016/j.lwt.2019.01.003.

10. Ozyurt, V.H.; Icier, F.; Otles, S. Effects of the thermosonication clarification on the rheological properties of apple juice. The Annals of the University Dunarea de Jos of Galati. Fascicle VI-Food Technology 2019, 43, 81-93, https://doi.org/10.35219/foodtechnology.2019.1.06.

11. Pan, L.H.; Liu, F.; Luo, S.Z.; Luo, J.P. Pomegranate juice powder as sugar replacer enhanced quality and function of set yogurts: Structure, rheological property, antioxidant activity and in vitro bioaccessibility. LWT 2019, 115, https://doi.org/10.1016/j.lwt.2019.108479.

12. Salinas, D.E.; Garvin, A.; Ibarz, R.; Ibarz, A. Effect of apple fibre addition and temperature on the rheological properties of apple juice and compensation study. LWT 2019, 116, https://doi.org/10.1016/j.lwt.2019.108456.

13. Cotrin, A.; Honorio-França, A.; França, E. Rheology analysis can be added in thermal stability test for design. Biointerface Research in Applied Chemistry 2016, 6, 1128-1136.

14. da Silva Pereira, G.; Leite, T.S.; Schmidt, F.L.; Cristianini, M.; Bolini, H.M.A. Effect of the homogenization process on the sensory and rheological properties in model system. Journal of Texture Studies 2020, 51, 352360, https://doi.org/10.1111/jtxs.12484.

15. Masselot, V.; Benkhelifa, H.; Cuvelier, G.; Bosc, V. Rheological properties of stabilizers at low temperatures in concentrated sucrose solutions. Food Hydrocolloids 2020, 103, https://doi.org/10.1016/j.foodhyd.2020.105691.

16. Chou, K.J.; Bao, L.; Ram, K.R.; Gu, C.; Chianf, P.C. Evaluation of nanoparticle formation feasibility upon wet milling based on physicochemical properties of drug molecules. Letters in Applied NanoBioScience 2015, 4, 231-235.

17. Kosma, V.A.; Beltsios, K.G. Modulus of elasticity \& design of polymer/hydroxyapatite and other synthetic \& natural polymer/ceramic composites of various geometries. Letters in Applied NanoBioScience 2016, 5, 369-388.

18. Xia, B.; Sun, D.-W. Applications of computational fluid dynamics (cfd) in the food industry: a review. Computers and Electronics in Agriculture 2002, 34, 5-24, https://doi.org/10.1016/S0168-1699(01)00177-6.

19. Gut, J.A.W.; Pinto, J.M.; Gabas, A.L.; Telis-Romero, J. Continuous Pasteurization of Egg Yolk: Thermophysical Properties and Process Simulation. Journal of Food Process Engineering 2005, 28, 181203, https://doi.org/10.1111/j.1745-4530.2005.00416.x.

20. Gratão, A.C.A.; Silveira, V.; Telis-Romero, J. Laminar flow of soursop juice through concentric annuli: Friction factors and rheology. Journal of Food Engineering 2007, 78, 1343-1354, https://doi.org/10.1016/j.jfoodeng.2006.01.006.

21. Huang, X.; Langrish, T.A.G.; Abbas, A.; Fletcher, D.F. Investigation of the flow patterns produced from sudden expansion geometries using pressure difference measurements and flow visualisation techniques. Chemical Engineering Research and Design 2018, 138, 280-291, https://doi.org/10.1016/j.cherd.2018.07.033.

22. Delhaye, J. Singular pressure drops in two-phase and heat transfer in the power and process industries. Bergles, A.E.; Collier, J.G.; Delhaye, J.M.; Hewitt, G.F.; Mayinger, F. Eds., Hemisphere, Washington, DC, 1981; pp. 124-149.

23. Guglielmini, G.; Muzzio, A.; Sotgia, G. The structure of two-phase in ducts with sudden contractions and its effectson the pressure drop. Proc. 4th World Conference on Experimental Heat Transfer Fluid mechanics and Thermodynamics (Bruxelles), June 2-6, 1997; pp. 1023-1036.

24. Nathan, G.J.; Hill, S.J.; Luxton, R.E. An axisymmetric 'fluidic' nozzle to generate jet precession. Journal of Fluid Mechanics 1998, 370, 347-380, https://doi.org/10.1017/S002211209800202X. 
25. Langrish, T.A.G.; Williams, J.; Fletcher, D.F. Simulation of the Effects of Inlet Swirl on Gas Flow Patterns in a Pilot-Scale Spray Dryer. Chemical Engineering Research and Design 2004, 82, 821-833, https://doi.org/10.1205/0263876041596661.

26. Guo, B.; Fletcher, D.F.; Langrish, T.A.G. Flow Patterns in Sudden Expansions and Their Relevance to Understanding the Behaviour of Spray Dryers. Developments in Chemical Engineering and Mineral Processing 2002, 10, 305-322, https://doi.org/10.1002/apj.5500100406.

27. Tsai, C.H.; Chen, H.T.; Wang, Y.N.; Lin, C.H.; Fu, L.M. Capabilities and limitations of 2-dimensional and 3-dimensional numerical methods in modeling the fluid flow in sudden expansion microchannels. Microfluidics and Nanofluidics 2007, 3, 13-18, https://doi.org/10.1007/s10404-006-0099-2.

28. Ahmed, W.H.; Ching, C.Y.; Shoukri, M. Pressure recovery of two-phase flow across sudden expansions. International Journal of Multiphase Flow 2007, 33, 575-594, https://doi.org/10.1016/j.ijmultiphaseflow.2006.12.005.

29. AOAC, Official methods for analysis. Volume II, 15th edn. Arlington, VA: Association of Official Analytical Chemists, 1984.

30. Barak, S.; Mudgil, D. Effect of guar fiber on physicochemical, textural and sensory properties of sweetened strained yoghurt. Biointerface Research in Applied Chemistry 2020, 10, 5564-5568, https://doi.org/10.33263/BRIAC103.564568.

31. Kirk, R.S.; Sawyer, R. Pearson's Composition and Analysis of Foods. 9th edn. London: Longman Scientific \& Technical, 1991; pp. 28-31.

32. Cenet, M.; Bozdogan, A.; Sezer, G.; Acar, L.; Ulukanli, Z. Antimicrobial activities, pollen diversity and physicochemical properties of natural honey from Southeastern Anatolia of Turkey. Advancements in Life Sciences 2017, 4(2), 47-54.

33. Bozdogan, A. Viscosity behavior of bitter orange (Citrus aurantium) juice as affected by temperature and concentration. CyTA - Journal of Food 2015, 13, 535-540, https://doi.org/10.1080/19476337.2015.1012120.

34. Kaya, A.; Belibağl1, K.B. Rheology of solid Gazıantep Pekmez. Journal of Food Engineering 2002, 54, 221226, https://doi.org/10.1016/S0260-8774(01)00205-9.

35. Bozdogan, A. Viscosity and physicochemical properties of cornelian cherry (Cornus mas L.) concentrate. Journal of Food Measurement and Characterization 2017, 11, 1326-1332, https://doi.org/10.1007/s11694017-9510-9.

36. Dimitreli, G.; Petridis, D.; Kapageridis, N.; Mixiou, M. Effect of pomegranate juice and fir honey addition on the rheological and sensory properties of kefir-type products differing in their fat content. LWT - Food Science and Technology 2019, 111, 799-808, https://doi.org/10.1016/j.lwt.2019.05.071.

37. Souza, L.D.S.S.; de Souza, T.P.; e Oliveira, R.L.; Junior, S.D.; de Freitas Hidalgo, A.; Pereira, A.M. Effect of temperature on the rheological behavior of sugary cassava. Emirates Journal of Food and Agriculture 2020, 125-130, https://doi.org/10.9755/ejfa.2020.v32.i2.2069.

38. Costa, T.D.S.; Rodrigues, A.M.D.C.; Pena, R.D.S. Rheological behavior of concentrated tucupi Food Science and Technology 2019, 39, 684-690, https://doi.org/10.1590/fst.04818.

39. Kobus, Z.; Nadulski, R.; Wilczyński, K.; Starek, A.; Zawiślak, K.; Rydzak, L.; Andrejko, D. Modeling of rheological properties of cloudy apple juice using master curve. CyTA - Journal of Food 2019, 17, 648-655, https://doi.org/10.1080/19476337.2019.1630484.

40. Meher, J.M.; Mazumdar, B.; Keshav, A. Rheological and functional properties of Roselle (Hibiscus sabdariffa) leaves puree. Potravinarstvo Slovak Journal of Food Sciences 2019, 13, 46-57, https://doi.org/10.5219/929.

41. Kamışl1, F.; Mohammed, D.A. Determination of Rheological Behavior of Some Molasses-Sesame Blends. Firat University Turkish Journal of Science and Technology 2019, 14, 23-32.

42. Rubio-Merino, J.; Rubio-Hernández, F.J. Activation energy for the viscoelastic flow: Analysis of the microstructure-at-rest of (water- and milk-based) fruit beverages. Food Chemistry 2019, 293, 486-490, https://doi.org/10.1016/j.foodchem.2019.05.012.

43. Ibarz, A.; Gonzalez, C.; Esplugas, S. Rheology of clarified fruit juices. III: Orange juices. Journal of Food Engineering 1994, 21, 485-494, https://doi.org/10.1016/0260-8774(94)90068-X.

44. Ibarz, A.; Garvin, A.; Costa, J. Rheological behaviour of sloe (Prunus spinosa) fruit juices. Journal of Food Engineering 1996, 27, 423-430, https://doi.org/10.1016/0260-8774(95)00024-0.

45. Giner, J.; Ibarz, A.; Garza, S.; Xhian-Quan, S. Rheology of clarified cherry juices. Journal of Food Engineering 1996, 30, 147-154, https://doi.org/10.1016/S0260-8774(96)00015-5. 